scondly, howerer careful he may be, this is very apt to iappen during sleep; hence the surgeon is frequently called mon to treat an un-united fracture of the humerus. Now, to lessen the risk of this evil, and to assist in its removal when it uniortunately cccurs, the improved splint, a drawing of which is here giren, has been constructed.

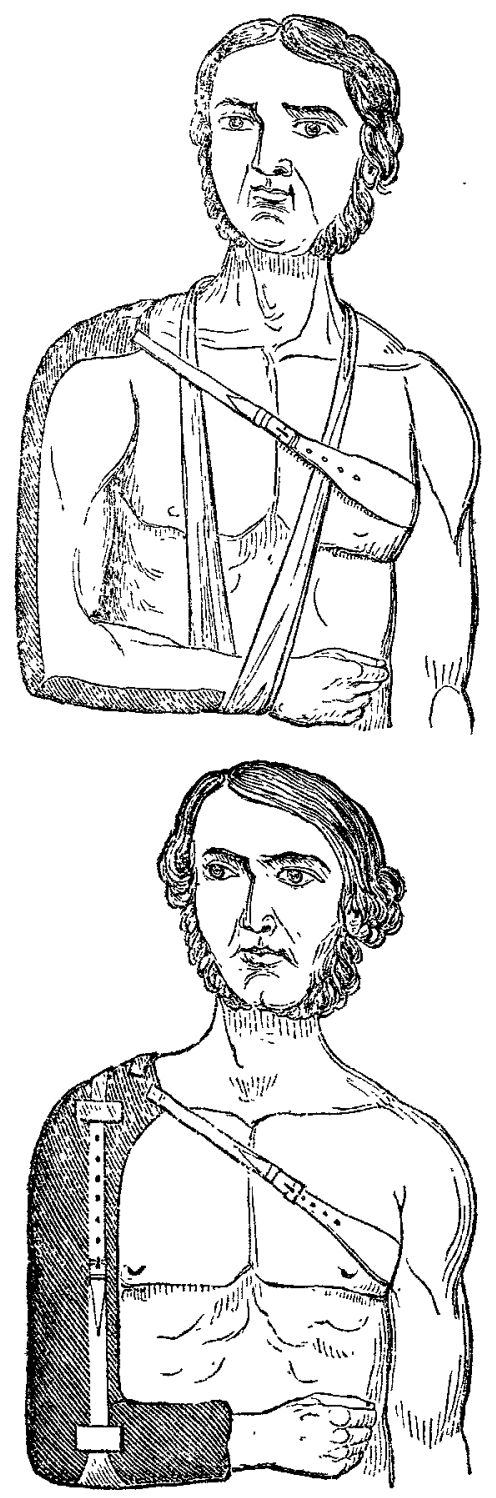

Instead of terminating below the shoulder, it will be seen that the outer half of the splint is extended over the shoulder, where a strap is attached, and passed round the body below the opposite axilla. In cases of simple fracture, this will be quite sufficient to keep the arm steady, but in cases of ununited fracture, an additional strap is added, which, passing below the elbow and over the shoulder, can be drawn by means of a buckle to any required degree of tightness. In this way the fractured ends of the bone can be brought into close contact. A simpler form of this splint may be found useful in cases of dislocations of the head of the humerus, or of the scapular end of the clavicle, and also in fractures of the neck of the humerus, and of the acromion process of scapula. In these, only one splint will be required, and instead of being cut as a right angle, so as to fit the exterior of the arm, it may be made strai, ht, and passed round the posterior of the arm; this, as the former, has a strap attached to the end of $\mathrm{it}$, which is also passed round below the opposite axilla. It is unnecessary that it should be made of so firm texture as the former; some light substance, such as Bristol loard, rendered firm with cioth pasted on both sides, will suffice; the strap also may be very light; perhaps a single fold of a bandare attached to the end of the splint, and passed round under the opposite axilla, will be quite sufficient. I think a light splint of this kind, for dislocations, would be felt of $v \in \mathrm{ry}$ little inconvenience by the patient, and would afford very suficient security against secondary dislocation. of crine, in this case a sling or bandage is essentially necessary, fir the splint being straight, and passing around the posterior jart of the arm, does not prevent its being stretched out as the nirst form of splint does.

Edinburgh, August, 184і.

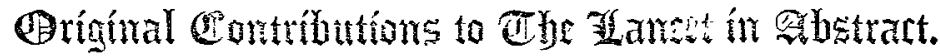

MEDICINE.

Case of Death by Hollowciy's Pills. By Thomas Grimmood, Esq., of Walton.

Mr. GrImwood narrates the case of a man, twenty-five years of age, long labouring under scrofulous disease of the femur and tibia, by whom he was consulted, on the 25 th of June last, for symptoms indicative of inflammation of the intestinal mucous membrane. It appears that the poor man, while in his ordinary state of health, was advised, with the hope of being cured of his old-standing complaint, to try Holloway's pills, beginning with five night and morning, gradually increasing the dose to ten, and then recurring to five. These instructions he punctually obeyed, with the effect of producing hypercatharsis, which he endured for about a week, in the belief that unless such an effect were caused, he could not obtain any benefit. This continued, and symptoms of greater severity setting in, Mr. Grimwood's assistance was sought, about ten days or a fortnight after the man commenced taking the pills. Ire then presented evident symptoms of peritonitis and enteritis in an advanced stage, attended with great exhaustion, from the effects of which he soon sank. A post-mortem examination does not appear to have been made.

\section{MEDICAL POLITICS.}

Poor-Law Medical Officers and Medical Etiquette.

A poor-law medical officer, whose communication is authenticated, writes to thank Mr. Wakley for his exertions in behalf of the class to which he belongs, and to express his belief, that but little will be done unless medical men unite to refuse undertaking the duties of parishes, except a proper salary be given. He fears, however, that this cannot be obtained, as the majority of practitioners have, he says, the spirit of hucksters, rather than of scientific gentlemen.

As a proof of the readiness of some practitioners to practise any dirty mancuvre to injure another, he cites the following:-

"In March last, a practitioner of forty years' standing was called to a patient of mine who was dying-in articulo mortisof puerperal peritonitis. The woman was pulseless and speechless. Without consulting me, and not knowing, of course, anything but what he learned from the attendants, of the history or previous treatment of the case, he swore I had bled her to death. Treating such a blackguard as a gentleman would be demeaning myself, therefore, when I afterwards met him in a public market-place, I requested an explanation, but nothing should I have but abuse, so I laid a stout horsewhip lustily about his back, which made him bellow like a calf; and I was afterwards bound over to keep the peace, but not fined, the magistrate giving my opponent a good lecture for the ungentlemanly aggravation he had given me."

* * The remedy adopted by our correspondent was a powerful one, and probably may prove effectual: it is not one, however, that can be adopted in all cases. With respect to the situation of union medical officers, we would direct his attention to a paragraph in this week's LANCET, under the head of "Medical News."

\section{Foreign Graduates and the Medical Registration Bill.} By J. Rowar, Esq.

Mr. Rowar writes to express his belief that the Medical Registration Bill will operate injuriously on those foreign graduates who have obtained their degrees by personal examination, and urges that they should be placed on at least an equal footing with the graduates of Aberdeen and St. Andrew's, whose diplomas have been procured by purchase only. If some clause to this effect be not inserted in the Bill, he anticipates that a determined opposition will be made to its progress through the House.

*** Mr. Rowan should bear in mind that English graduates of foreign universities, who have undergone the required examinations, are but few in number as compared with those who hold their diplomas by purchase only; and of these few, the najority have not acquired academical status by study at the university, but merely by a mere formal examination, following a "pleasant trip up the Rhine." These gentlemen had better rost satisfied with their English gualifications as surgeons, or else present themselves for examination at one of the Colleges of Physicians, and thus acquire a legal title to practise as such, of which they are at present uupossessed. 